Jurnal Akuntansi dan Bisnis: Jurnal Program studi Akuntansi, 6 (1) Mei 2020.

ISSN 2443-3071 (Print) ISSN 2503-0337 (Online). DOI: 10.31289/jab.v6i1.2752

JURNAL AKUNTANSI DAN BISNIS

Jurnal Program Studi Akuntansi

Available online http://ojs.uma.ac.id/index.php/jurnalakundanbisnis

\title{
PENGARUH KUALITAS E-GOVERNMENT TERHADAP KEPUASAN PENGGUNA E-FILING: STUDI KASUS WAJIB PAJAK DI SURAKARTA
}

\author{
Gunawan Setyo Utomo ${ }^{a *}$, Kartika Hendra Titisari ${ }^{a}$, Anita Wijayanti ${ }^{a}$ \\ ${ }^{a}$ Program Studi Akuntansi, Universitas Islam Batik Surakarta
}

Diterima Juli 2019, Disetujui November 2019, Dipublikasikan Mei 2020

\begin{abstract}
Abstrak
Penelitian ini bertujuan untuk mengetahui pengaruh pengaruh kualitas sistem, kualitas informasi, dan kualitas layanan terhadap kepuasan pengguna E-filing di Surakarta. Populasi dan sampel dalam penelitian ini adalah wajib pajak orang pribadi yang terdaftar di Kantor Pelayanan Pajak Pratama Surakarta tahun 2019. Teknik pengambilan data penelitian ini menggunakan teknik incidental sampling, dan penentuan jumlah sampel menggunakan rumus slovin dengan sampel penelitian sebanyak 100 responden. Data yang digunakan dalam penelitian ini adalah kuesioner dengan menggunakan skala likert. Teknik analisis data yang digunakan dalam penelitian ini adalah regresi linier berganda. Hasil analisis yang dilakukan dalam penelitian ini menunjukkan bahwa ada pengaruh positif kualitas sistem dan kualitas layanan terhadap kepuasan pengguna E-filing. Sedangkan kualitas informasi tidak bepengaruh terhadap kepuasan pengguna $E$-filing.
\end{abstract}

Kata Kunci: Kualitas Sistem, Informasi, Layanan, Kepuasan Pengguna.

\begin{abstract}
This study aims to determine the effect of system quality, information quality, and service quality on Efiling user satisfaction in Surakarta. The population and sample in this study are individual taxpayers registered at the Pratama Surakarta Tax Office in 2019. The data collection technique of this study uses incidental sampling techniques, and the determination of the number of samples using Slovin formula with a sample of 100 respondents. The data used in this study is a questionnaire using a Likert scale. The data analysis technique used in this study is multiple linear regressions. The results showed the analysis there is a positive influence on system quality and service quality on E-filing user satisfaction. While the quality of the information does not affected E-filing user satisfaction.
\end{abstract}

Keyword: System Quality, Information, Services, User Satisfaction

How To Cite: Gunawan Setyo Utomo, Kartika Hendra Titisari, Anita Wijayanti (2020) Pengaruh Kualitas EGovernment Terhadap Kepuasan Pengguna E-Filing: Studi Kasus Wajib Pajak Di Surakarta. Jurnal Akuntansi dan Bisnis: Jurnal Program Studi Akuntansi, 6 (1): 13-21

* email: gunawan.setyo23@gmail.com

\section{PENDAHULUAN}

Dengan semakin meluasnya pemanfaatan teknologi informasi dan komunikasi, muncul berbagai peluang untuk meningkatkan kegiatan pelayanan sektor publik sehingga dapat berjalan lebih efektif dan efisien, Oleh karena itu, pemerintah diharapkan mampu terus menggali potensi pemanfaatan perkembangan teknologi informasi dan komunikasi, diantaranya transformasi pelaksanaan kegiatan pemerintahan melalui $e$ Government. Salah satu tujuan implementasi e-Government adalah agar lembaga pemerintah mampu menyediakan pelayanan publik yang lebih baik. Dalam kaitan ini dibutuhkan komitmen yang kuat dari pemerintah untuk merintis dan memulai hal yang baru dalam birokrasi. Sosiawan, E. A. (2015). 
Dalam upaya pemerintah dalam meningkatkan kualitas layanan e-Government pada bidang perpajakan, Direktorat Djendral Pajak melakukan reformasi administrasi perpajakan dengan memodernisasi sistem administrasi perpajakan. Sistem administrasi modern berbasis e-sistem seperti e-Registration, e-SPT, e-Faktur, e-Billing, dan E-filing. Tahun 2019 Direktur Jenderal Pajak Peraturan Dirjen Pajak pengeluarkan peraturan baru Nomor PER-02/PJ/2019 mengenai Tata Cara Penyampaian, Penerimaan, dan Pengolahan Surat Pemberitahuan (SPT). Penyampaian SPT oleh wajib pajak kini dilakukan secara online melalui E-filing. Peraturan terbaru ini merupakan pelaksanaan dari Peraturan Menteri Keuangan (PMK) Nomor 9/PMK.03/2018. Dalam PER-02 ini, salah satu pokok perubahan yang ditegaskan adalah mengenai kewajiban setiap wajib pajak menyampaikan SPT online melalui aplikasi $E$-filing.

Model kesuksesan sistem informasi telah banyak dikembangkan oleh para peneliti (Bailey dan Person 1983, DeLone dan McLean 1992, Seddon 1997, Rai et al., 2002). Dari beberapa model kesuksesan sistem informasi tersebut, model DeLone dan McLean (1992) banyak mendapat perhatian dari para peneliti selanjutnya (Mc Gill et al., 2003). Livari (2005) juga menguji secara empiris Model DeLone dan McLean (D dan M) tersebut, Tujuan penelitian ini ingin mengaitkan dan membuktikan penelitian tersebut bahwa kesuksesan sistem informasi dipengaruhi oleh kualitas sistem informasi dan kualitas informasi yang dihasilkan dari sistem yang bersangkutan serta kualitas layanan.

\section{Teori Information Sytem Succes DeLone \& McLean}

Konsep kesuksesan sistem informasi merupakan suatu konsep yang digunakan dalam mengevaluasi sistem informasi. Penelitian ini mengacu pada Model DeLone \& McLean (2003) untuk mengetahui suatu efektivitas sistem informasi yang akan diteliti, sedangkan variabel yang akan digunakan merujuk pada penelitian Livari (2005) yang meliputi kualitas sistem (system quality), kualitas informasi (information quality), kualitas layanan (service quality), kepuasan pengguna (user satisfaction).

\section{Kualitas Sistem (System Quality)}

Menurut DeLone dan McLean (2003), kualitas sistem adalah karakteristik dari kualitas yang diinginkan dari sistem informasi dan informasi berkualitas yang diinginkan informasi karakteristik produk. Kualitas sistem yaitu kualitas pada kombinasi hardware dan software dalam sistem informasi. Dapat disimpulkan bahwa kualitas sistem adalah karakteristik dari kualitas yang diinginkan dari sistem itu sendiri yang merupakan kombinasi dari beberapa unsur sehingga menghasilkan informasi yang berkualitas dan dapat pembantu pengambilan keputusan.

\section{Kualitas Informasi}

Menurut Suwardjono (2001:58) kualitas informasi adalah karakteristik yang melekat pada informasi sehingga informasi bermakna bagi pemakai dan memberi keyakinan kepada pemakai sehingga bermanfaat dalam keputusan. Disimpulkan bahawa kualitas informasi adalah karakteristik isi, bentuk, dan waktu yang melekat pada informasi yang memberikan nilai dan manfaat bagi pengguna dan memberi keyakinan kepada pengguna untuk menggunakan informasi tersebut.

\section{Kualitas Layanan}

Bitner (2000) kualitas pelayanan merupakan keseluruhan kesan konsumen terhadap inferioritas / superioritas organisasi beserta jasa yang ditawarkan. Parasuraman (2005) mendefinisikan kualitas pelayanan (servqual) sebagai suatu konsep 
yang secara tepat mewakili inti kinerja suatu jasa, yaitu perbandingan terhadap keterandalan (excellence) dalam counter service yang dilakukan oleh konsumen.Dari teori diatas disimpulkan bahwa kualitas layanan adalah konsep yang mewakili kinerja organisasi yang menawarkan jasa dengan ukuran perbandingan kualitas jasa terhadap tanggapan yang diberikan oleh konsumen.

\section{E-Government}

Menurut The World Bank Group (Suaedi \& Wardianto, 2010:54), E-Government ialah sebagai upaya pemanfaatan informasi dan teknologi komunikasi untuk meningkatkan efisiensi dan efektivitas, transparansi dan akuntabilitas pemerintah dalam memberikan pelayanan publik secara lebih baik. Wibawa (2009:113), EGovernment adalah penggunaan teknologi informasi oleh instansi pemerintah seperti Wide Area Networks (WAN) internet, moble competing, yang dapat digunakan untuk membangun hubungan dengan masyarakat, dunia usaha dan instansi pemerintah lainnya. Berdasarkan pengertian diatas maka dapat disimpulkan bahwa $e$ Government adalah pemanfaatan kemajuan teknologi informasi guna meningkatkan efektivitas dan efesiensi pelayanan pemerintah kepada publik agar terjalin hubungan yang baik oleh kedua pihak.

\section{E-Filing}

Melalui Keputusan Direktorat Jenderal Pajak (DJP) Nomor Kep-88/PJ/2004 pada bulan Mei tahun 2004 secara resmi sistem E-filing diluncurkan. Menurut Peraturan Direktorat Jenderal Pajak No. 47/PJ/2008 pasal 1 menyebutkan bahwa E-filing adalah suatu cara penyampaian SPT dan penyampaian pemberitahuan perpanjangan SPT Tahunan secara elektronik yang dilakukan secara online dan real time melalui Penyedia Jasa Aplikasi (ASP).

Kerangka Konseptual Penelitian

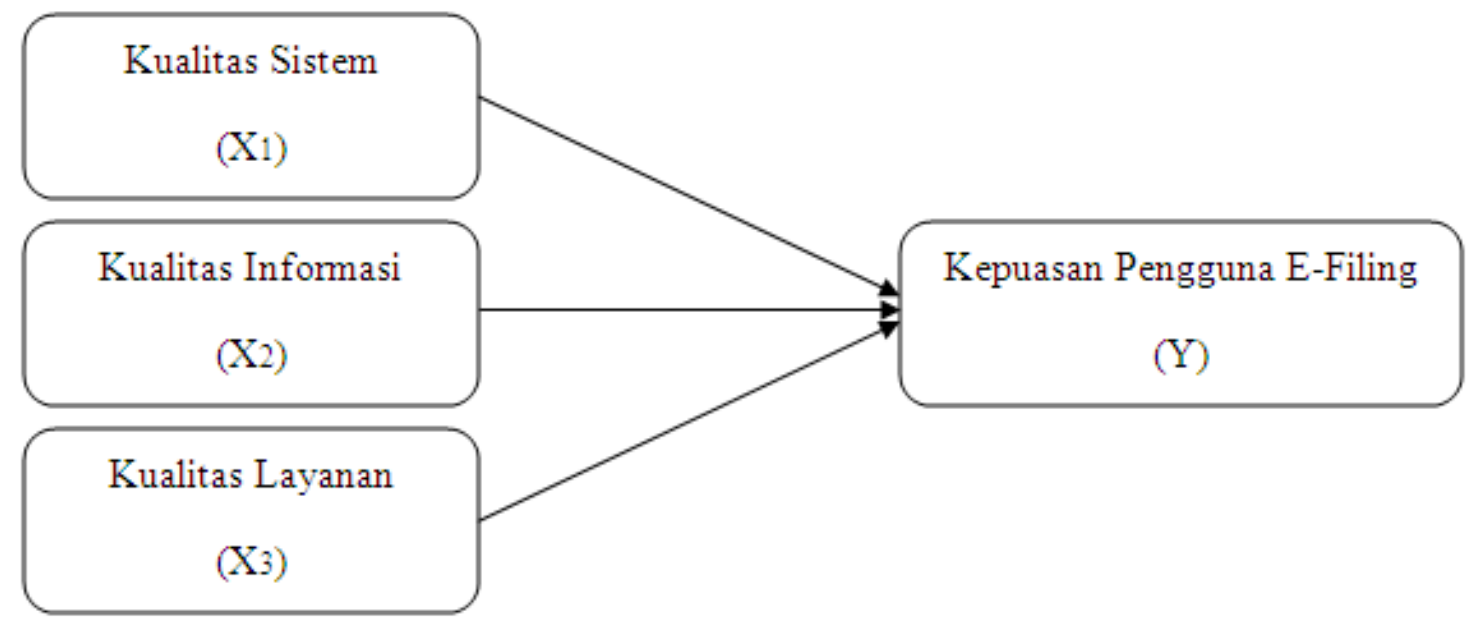

Gambar 1 Kerangka Konseptual Penelitian

\section{Pengembangan Hipotesis}

Kualitas sistem berpengaruh positif terhadap kepuasan pengguna $E$-filing.

Kualitas sistem adalah seberapa baik fitur maupun karakteristik yang dimiliki oleh sistem informasi dalam kemudahan penggunaannya. Kualitas sistem ini meliputi kemudahan penggunaan, fleksibilitas sistem, keandalan sistem, kemudahan pembelajaran, dan waktu respon yang baik (Petter et al. 2008). 
Kepuasan pengguna yaitu, respon atau perasaan pengguna setelah menggunakan sebuah sistem informasi. Secara keseluruhan kepuasan pengguna dipengaruhi oleh kualitas informasi, kualitas sistem, dan kualitas layanan. Sehingga instrumen yang digunakan dalam mengukur tingkat kepuasan pengguna yaitu dengan melihat tingkat kepuasan mengenai laporan atau output yang dihasilkan, website, dan layanan dukungan dari penyedia sistem (Petter et al. 2008).

Sehingga apabila sistem tersebut mudah untuk digunakan maka hal tersebut akan meningkatkan kepuasan penggunanya. Dalam penelitian yang dilakukan oleh Ginting \& Marlina, (2017) menunjukkan bahwa kualitas sistem berpengaruh positif terhadap kepuasan pengguna E-filing. Demikian juga dengan hasil penelitian Prasojo \& Pratomo (2015), memberikan bukti empiris bahwa kualitas sistem berpengaruh positif terhadap kepuasan pengguna.

H1 : Kualitas sistem berpengaruh positif terhadap kepuasan pengguna $E$-filing.

\section{Kualitas informasi berpengaruh positif terhadap kepuasan pengguna $E$-filing.}

Kualitas informasi adalah karakterisitik dari ouput yang disajikan dalam sebuah sistem informasi yaitu meliputi manajemen laporan dan halaman web (Petter dan Mclean 2009). Hal ini mengukur seberapa baik output yang dihasilkan dari sistem informasi yang digunakan. Semakin baik kualitas informasi, akan semakin tepat pula keputusan yang diambil.

Hasil penelitian Adhikari \& Ram (2017) menunjukan kualitas informasi berpengaruh positif terhadap kepuasan wajib pajak dalam menggunakan aplikasi $E$ filing. Hasil penelitian Islam et al. (2012) menjelakan bahwa kualitas informasi berpengaruh terhadap kepuasan pengguna. Kualitas informasi yang baik diprediksi akan berpengaruh terhadap semakin tingginya kepuasan pengguna.

H2: Kualitas informasi berpengaruh positif terhadap kepuasan pengguna $E$-filing.

\section{Kualitas layanan berpengaruh positif terhadap kepuasan pengguna $E$-filing.}

Kualitas layanan merupakan persepsi pengguna atas jasa yang diberikan oleh penyedia paket program sistem informasi. Kualitas layanan sebagai perbandingan antara harapan pelanggan dan persepsi mereka tentang kualitas layanan pelanggan yang diberikan (Livari, 2005).

Veeramootoo et al. (2018) dalam penelitiannya menyatakan bahwa kualitas pelayanan berpengaruh positif terhadap kepuasan dalam penggunanaan aplikasi $E$-filing. Hasil penelitian Widiani \& Abdullah (2018) mendukung bukti empiris bahwa kualitas layanan berpengaruh positif terhadap kepuasan pengguna.

H3 : Kualitas layanan berpengaruh positif terhadap kepuasan pengguna $E$-filing.

\section{METODE PENELITIAN}

Jenis Penelitian ini adalah penelitian deskriptif kuantitatif. Variabel dalam penelitian ini terdiri dari variabel dependen yaitu kepuasan pengguna e-filing, sendangkan variabel independen adalah kualitas sistem, kualitas informasi, kualitas layanan. Populasi dalam penelitian ini adalah wajib pajak OP di Surakarta yang terdaftar pada KPP Pratama Surakarta sampai dengan tahun 2019. Sampel dalam penelitian ini sebanyak 100 responden yang dihitung menggunakan rumus slovin, dengan instrument penelitian berupa kuesioner yang diukur mengunkan skala likert. Teknik pengumpulan sampel dalam penelitian ini menggunakan metode incidental sampling, dengan instrument penelitian menggunakan kuesioner. Metode pengumpulan sampel dalam 
penelitian ini mengunakan sampling incidental. Teknik analisis data dalam penelitian ini menggunkan regresi linier sederhana dan analisis regresi linier berganda.

\section{HASIL DAN PEMBAHASAN}

\section{Deskripsi Statistik}

Tabel 1. Kuesioner yang Digunakan Dalam Penelitian

\begin{tabular}{|c|c|c|}
\hline Keterangan & Jumlah & Persentase \\
\hline Tanggapan yang diterima & 118 & $100 \%$ \\
\hline Tanggapan yang gugur & 18 & $15 \%$ \\
\hline Tanggapan yang dipakai & 100 & $85 \%$ \\
\hline \multicolumn{3}{|c|}{ Tabel 2. Hasil Data Responden } \\
\hline Keterangan & Jumlah & Persentase \\
\hline \multicolumn{3}{|l|}{ Jenis Kelamin } \\
\hline Laki-laki & 58 & $58 \%$ \\
\hline Perempuan & 42 & $42 \%$ \\
\hline \multicolumn{3}{|l|}{ Umur } \\
\hline $20-40$ Tahun & 61 & $61 \%$ \\
\hline $40<$ Tahun & 39 & $39 \%$ \\
\hline \multicolumn{3}{|l|}{ Pendidikan Terakhir } \\
\hline SMA/SMK & 33 & $33 \%$ \\
\hline D3 & 17 & $17 \%$ \\
\hline S1 & 41 & $41 \%$ \\
\hline S2 & 9 & $9 \%$ \\
\hline \multicolumn{3}{|l|}{ Pengalaman $E$-filing } \\
\hline$>3$ Tahun & 20 & $20 \%$ \\
\hline 1-3 Tahun & 60 & $60 \%$ \\
\hline$<1$ Tahun & 20 & $20 \%$ \\
\hline
\end{tabular}

\section{Hasil Uji Instrumen Penelitian}

Tabel 3. Hasil Pengujian Validitas Kualitas Sistem

\begin{tabular}{ccccc}
\hline Butir Pernyataan & r Hitung & r Tabel & Kriteria & Keterangan \\
\hline KS_1 & 0,734 & 0.197 & r hitung $>r$ tabel & Valid \\
KS_2 & 0,685 & 0.197 & r hitung $>$ r tabel & Valid \\
KS_3 & 0,623 & 0.197 & r hitung $>r$ tabel & Valid \\
KS_4 & 0,648 & 0.197 & r hitung $>r$ tabel & Valid \\
KS_5 & 0,648 & 0.197 & r hitung $>r$ tabel & Valid \\
KS_6 & 0,616 & 0.197 & r hitung $>$ r tabel & Valid \\
KS_7 & 0,659 & 0.197 & r hitung $>r$ tabel & Valid \\
KS_8 & 0,589 & 0.197 & r hitung $>r$ tabel & Valid \\
\hline
\end{tabular}

Tabel 4. Hasil Pengujian Validitas Kualitas Informasi

\begin{tabular}{ccccc}
\hline Butir Pernyataan & r Hitung & r Tabel & Kriteria & Keterangan \\
\hline KI_1 & 0,616 & 0.197 & r hitung $>$ r tabel & Valid \\
KI_2 & 0,657 & 0.197 & r hitung $>$ r tabel & Valid \\
KI_3 & 0,755 & 0.197 & r hitung $>r$ tabel & Valid \\
KI_4 & 0,703 & 0.197 & r hitung $>$ r tabel & Valid \\
KI_5 & 0,767 & 0.197 & r hitung $>$ r tabel & Valid \\
KI_6 & 0,735 & 0.197 & r hitung $>$ r tabel & Valid \\
KI_7 & 0,638 & 0.197 & r hitung $>r$ tabel & Valid \\
KI_8 & 0,626 & 0.197 & r hitung $>r$ tabel & Valid \\
\hline
\end{tabular}


Gunawan Setyo Utomo, Kartika Hendra Titisari, Anita Wijayanti (2020) Pengaruh Kualitas E-Government Terhadap Kepuasan Pengguna E-Filing...

Tabel 5. Hasil Pengujian Validitas Kualitas Layanan

\begin{tabular}{|c|c|c|c|c|}
\hline Butir Pernyataan & r Hitung & r Tabel & Kriteria & Keterangan \\
\hline KI_1 & 0,633 & 0.197 & r hitung $>r$ tabel & Valid \\
\hline KI_2 & 0,626 & 0.197 & $r$ hitung $>r$ tabel & Valid \\
\hline KI_3 & 0,715 & 0.197 & r hitung $>r$ tabel & Valid \\
\hline KI_4 & 0,648 & 0.197 & r hitung $>r$ tabel & Valid \\
\hline KI_5 & 0,655 & 0.197 & r hitung $>r$ tabel & Valid \\
\hline KI_6 & 0,691 & 0.197 & $r$ hitung $>r$ tabel & Valid \\
\hline KI_7 & 0,732 & 0.197 & r hitung $>r$ tabel & Valid \\
\hline KI_8 & 0,673 & 0.197 & r hitung $>r$ tabel & Valid \\
\hline \multicolumn{5}{|c|}{ Tabel 6. Hasil Pengujian Reliabilitas } \\
\hline Butir Pernyataan & $\begin{array}{c}\text { Cronbach's } \\
\text { Alpha }\end{array}$ & r Tabel & Kriteria & Keterangan \\
\hline Kualitas Sistem & 0,800 & 0.197 & Cronbach's Alpha > r tabel & Reliabel \\
\hline Kualitas Informasi & 0,840 & 0.197 & Cronbach's Alpha > r tabel & Reliabel \\
\hline Kualitas Layanan & 0,826 & 0.197 & Cronbach's Alpha $>$ r tabel & Reliabel \\
\hline Kepuasan Pengguna E-filing & 0,848 & 0.197 & Cronbach's Alpha > r tabel & Reliabel \\
\hline
\end{tabular}

Hasil Uji Asumsi Klasik

Tabel 7. Hasil Uji Normalitas

\begin{tabular}{cccc}
\hline $\mathrm{N}$ & Asymp Sig & Kriteria & Keterangan \\
\hline 100 & 0,22 & $>0,05$ & Data terdistribusi normal \\
\hline
\end{tabular}

Tabel 8. Hasil Uji Multikolinearitas

\begin{tabular}{cccccc}
\hline Variabel & Tolerance & Kriteria & VIF & Kriteria & Keterangan \\
\hline Kualitas Sistem & 0,452 & $>0,10$ & 2,212 & $<10$ & Tidak terjadi Multikolinearitas \\
Kualitas Informasi & 0,417 & $>0,10$ & 2,399 & $<10$ & Tidak terjadi Multikolinearitas \\
Kualitas Layanan & 0,436 & $>0,10$ & 2,296 & $<10$ & Tidak terjadi Multikolinearitas \\
\hline
\end{tabular}

Tabel 9. Hasil Uji Autokorelasi

\begin{tabular}{cccccc}
\hline DW & $\mathrm{dL}$ & $\mathrm{dU}$ & $4-\mathrm{dL}$ & $4-\mathrm{dU}$ & Keterangan \\
\hline 1,667 & 1,6131 & 1,7364 & 2,3869 & 2,2636 & Kesimpulan tidak pasti \\
\hline
\end{tabular}

Tabel 10. Hasil Pengujian Run Test

\begin{tabular}{cccc}
\hline $\mathrm{N}$ & Asymp Sig (2-tailed) & Kriteria & Keterangan \\
\hline 100 & 0,159 & $>0,05$ & Data residual acak \\
\hline
\end{tabular}

\section{Hasil Uji Regresi Linier Berganda}

Tabel 11. Hasil Uji Kelayakan Model (Uji F)

\begin{tabular}{ccccc}
\hline F Hitung & F Tabel & Kriteria & Sig & Kesimpulan \\
\hline 32,116 & 2,70 & F hitung $>$ F tabel & 0,000 & Layak \\
\hline
\end{tabular}

Tabel 12. Hasil Uji Hipotesis (Uji t)

\begin{tabular}{cccccc}
\hline Variabel & t Hitung & t Tabel & Kriteri & Sig. & Kesimpulan \\
\hline Kualitas Sistem & 3,196 & 1,985 & t hitung $>$ t tabel & 0,002 & H1 Diterima \\
Kualitas Informasi & 0,178 & 1,985 & t hitung $>$ t tabel & 0,859 & H2 Ditolak \\
Kualitas Layanan & 3,785 & 1,985 & t hitung $>$ t tabel & 0,000 & H3 Diterima \\
\hline
\end{tabular}

Tabel 13. Hasil Uji Koefisien Determinasi (Adjusted $\mathrm{R}^{2}$ )

\begin{tabular}{cc}
\hline Adjusted $R$ Square & Keterangan \\
\hline 0,485 & Variabel independen mempengaruhi sebesar $48,5 \%$ \\
\hline
\end{tabular}




\section{Pembahasan}

Kualitas Sistem Berpengaruh Positif Terhadap Kepuasan Pengguna E-Filing (H1)

Hasil analisis yang tersaji pada Tabel 12 menjelaskan bahwa kualitas sistem berpengaruh positif terhadap kepuasan pengguna E-filing. Hasil ini mendukung penelitian sebelumnya yang dilakukan oleh Ginting \& Marlina, (2017), hasil penelitiannya menunjukkan bahwa kualitas sistem berpengaruh positif terhadap kepuasan pengguna E-filing. Semakin tinggi kualitas sistem E-filing maka dapat meningkatkan kepuasan penggunanya, yaitu wajib pajak. Kualitas sistem E-filing yang tinggi dapat mempermudah dan memperlancar dalam pelaporan SPT, hal tersebut dapat membantu wajib pajak dalam memenuhi kewajibanya dalam melaporkan SPT secara efisien dan efektif. Semakin tinggi kualitas sistem membuat kepuasan pengguna atau wajib pajak menjadi meningkat Hasil ini bertolak belakang dengan hasil penelitian yang dilakukan oleh Hanadia (2017) yang menjelaskan bahwa kualitas sistem tidak berpengaruh terhadap kepuasan pengguna.

\section{Kualitas Informasi Berpengaruh Positif Terhadap Kepuasan Pengguna E-Filing (H2)}

Hasil analisis yang tersaji pada Tabel 12 menjelaskan bahwa kualitas informasi tidak berpengaruh terhadap kepuasan pengguna E-filing. Hasil ini bertolak belakang dengan penelitian sebelumnya yang dilakukan oleh Adhikari \& Ram (2017) menunjukan kualitas informasi berpengaruh positif terhadap kepuasan wajib pajak dalam mengunakan aplikasi E-filing. Hasil ini sejalan dengan penelitian yang dilakukan oleh Ritonga \& Yanto (2013) yang menyatakan bahwa kualitas informasi tidak berpengaruh terhadap kepuasan pengguna. Sistem E-filing diperuntukan untuk memudahkan wajib pajak dalam penyampaian SPT, akan tatapi didalam sistem/website $E$-filing minim dalam memuat informasi mengenai perpajak. Sehingga kualitas informasi yang terkandung dalam sistem $E$-filing tidak mempengaruhi kepuasan pengguna.

\section{Kualitas Informasi Berpengaruh Positif Terhadap Kepuasan Pengguna E-Filing (H3)}

Hasil analisis yang tersaji pada Tabel 12 menjelaskan bahwa kualitas layanan berpengaruh positif terhadap kepuasan pengguna E-filing. Hasil ini mendukung penelitian sebelumnya yang dilakukan oleh Veeramootoo et al. (2018) dalam penelitiannya menyatakan bahwa kualitan pelayanan berpengaruh positif terhadap kepuasan dalam penggunanaan aplikasi $E$-filing. Kualitas layanan dalam sistem $E$-filing menyederhanakan dan menstandarkan proses perpajakan dalam pelaporan SPT, hal tersebut dapat memberikan layanan perpajakan yang lebih baik. Semakin meningkatnya kualitas layanan berdampak pada peningkatan kepuasan pengguna atau wajib pajak.

\section{SIMPULAN}

Uji validitas dan reliabilitas menunjukkan bahwa pertanyan yang diajukan dalam kuesioner untuk mengukur varibel-variabel dinyatakan valid dan reliabel. Analisis korelasi menunjukkan variabel kualitas sistem, kualitas informasi, dan kualitas layanan berkorelasi positif dengan kepuasan pengguna E-filing. Jika dilihat dari signifikansinya hanya variabel kualitas sistem dan kualitas layanan yang signifikan. Dari hasil pengujian hipotesis 1 menyatakan bahwa kualitas sistem berpengaruh positif terhadap kepuasan pengguna E-filing. Hasil ini didukung oleh penelitian sebelumnya yang dilakukan oleh Ginting \& Marlina, (2017). Hasil uji hipotesisi 2 menyatakan kualitas informasi tidak berpengaruh terhadap kepuasan pengguna E-filing. Hasil ini bertolak belakang dengan penelitian sebelumnya yang dilakukan oleh Adhikari \& Ram (2017). Dari hasil pengujian hipotesis 3 menunjukkan kualitas layanan berpengaruh positif terhadap kepuasan 
pengguna E-filing.Hasil ini mendukung penelitian sebelumnya yang dilakukan oleh Veeramootoo et al (2018). Hasil koefisiensi determinasi menunjukkan bahwa besaran persentase sumbangan dari variabel independen terhadap kepuasan pengguna Efilingsebesar $48.5 \%$ dan sisanya $51,5 \%$ dipengaruhi oleh variabel lain yang tidak dimasukkan dalam model ini. Penelitian ini mengindikasikan bahwa pertama Pemerintah Indonesia sedang berupaya dalam meningkatkan kualitas pelayanan dengan mengedepankan efektifitas, efisiensi dan transparansi melalui E-Government, yang kedua E-filing merupakan salah satu produk sistem E-Government yang dibuat oleh Direktorat Djendral Pajak guna meningkatkan efektifitas dan efisiensi dalam pelaporan SPT, yang ketiga Kualitas sistem dan kualitas layanan berpengaruh positif terhadap kepuasan pengguna E-filing, dan yang terakhir Kualitas informasi tidak berpengaruh terhadap kepuasan pengguna E-filing, E-filing diperuntukkan untuk pelaporan SPT sehingga dalam situs / website E-fling tidak memuat informasi yang up to date mengenai peraturan dan kebijakan perpajakan. Informasi yang termuat dalam situs E-filing berupa data wajib pajak, panduan singkat dalam pengisian formulir elektronik dan laporan atas SPT yang sudah berhasil dilaporkan.

Dalam penelitian ini, penulis menyadari akan adanya beberapa keterbatasan antara lain hasil penelitian ini menunjukkan bahwa determinasi pengaruh variabel bebas terhadap variabel terikat sebesar 48,5\%. Sehingga ada keterbatasan karena ada variabel lain yang mempengaruhi kepuasan pengguna $E$-filing untuk wajib pajak yang terdaftar di KPP Pratama Surakarta, selanjutnya penelitian ini hanya berfokus meneliti wajib pajak orang pribadi, sedangkan wajib pajak ada dua jenis yaitu wajib pajak perorangan pribadi dan wajib pajak badan usaha. Sehingga tidak dapat dibandingkan dalam pemenuhan kewajiban perpajakannya, dan penelitian ini hanya meneliti wajib pajak orang pribadi pada KPP Pratama Surakarta, jadi hasilnya tidak dapat digeneralisasikan pada wajib pajak di KPP lainnya. Untuk penelitian selanjutnya akan lebih baik jika memperluas objek penelitian dengan menambahkan variabel lain seperti persepsi kegunaan, pengetahuan teknologi untuk menilai kepuasan pengguna E-filing, sebaiknya juga dapat mencangkup populasi yang lebih luas seperti wajib pajak orang pribadi dan wajib pajak badan usaha agar dapat dikaji lebih luas. Untuk petugas pajak disarankan agar memberikan penyuluhan ataupun sosialisasi secara rutin kepada wajib pajak terkait peraturan perpajakan yang selalu update tiap tahunnya, serta untuk Direktorat Djendral Pajak agar terus mengembangkan inovasi terutama dalam bidang teknologi guna meningkatkan kualitas pelayanan terhadap wajib pajak sehingga diharapkan dapat tercipta sistem perpajakan yang semakin baik.

\section{DAFTAR PUSTAKA}

Adhikari, \& Ram, R. (2017). Kepuasan Wajib Pajak Dengan E-Filling Pajak Penghasilan (E-PPN). Asia Selatan Jurnal Kebijakan Dan Pemerintahan Vol 41 Nomor 2 , 57-74.

Bitner, M. J., Brown, S. W., \& Meuter, M. L. (2000). Technology Infusion In Service Encounters. Journal Of The Academy Of Marketing Science. , 138-149.

Delone, W. H., \& Mclean, E. R. (2003). The Delone And Mclean Model Of Information Systems Success: A Ten-Year Update. Journal Of Management Information Systems Vol. 19, No. 4 , 9-30.

Ginting, D. B., \& Marlina, M. R. (2017). Analisis Pengaruh Kualitas Sistem, Kualitaslayanan, Kualitas Informasi, Kemudahan Penggunaan, Dan Persepsi Manfaat Terhadap Kepuasanpengguna Fasilitas EFiling. Media Informatika Vol.16 No.1, 21-31.

Hanadia, N., Rahayu, S., \& Zultilisna, D. (2017). Pengaruh Kualitas Sistem, Perceived Usefulness, Dan Kualitas Informasi Terhadap Kepuasan Pengguna (Studi Kasus Terhadapsistem Dashboard Pdam Tirta Raharja 2017). E-Proceeding Of Management : Vol.4, No.3 , 2707-2714. 
Islam, M. A., Yusuf, D. H., Yusoff, W. S., \& Johari, A. N. (2012). Faktor Yang Mempengaruhi Kepuasan Pengguna Dalam Sistem E-Filing Pajak Penghasilan Malaysia. African Journal of Business Management Vol. 6 , 6447-6455.

Kenneth C Laudon, J. P. (2000). Organization And Technology In The Netwod Enterprise. Management Information Systems .

Livari, J. (2005). An Empirical Test Of The Delone-Mclean Model Of Information System Success. The DATA BASE For Advances In Information Systems - Spring Vol. 36 No. 2 , 8-27.

Parasuraman, A. P., Zeithaml, V. A., \& Malhotra, A. (2005). E-S-Qual: A Multiple-Item Scale For Assessing Electronic Service Quality. Journal Of Service Research Vol. 7, No. 3, 213-233.

Prasojo, L. H., \& Pratomo, D. (2015). Pengaruh Kualitas Informasi, Kualitas Sistem, Dan Kualitas Layanan Aplikasi Rail Ticket System (Rts) Terhadap Kepuasan Pengguna Sistem. E-Proceeding Of Management : Vol.2, No.1, 555-562.

Pratomo, D., \& Yuliandhary, W. S. (2016). Faktor-Faktor Yang Mempengaruhi Kesuksesan Sistem Informasi Kehadiran. Jurnal Ekono Insentif Kopwil4, Vol:10 No. 2 , 25-32.

Ritonga, F., \& Yanto, F. F. (2013). Pengaruh Kualitas Sistem Informasi, Kualitas Informasi, Dan Kualitas Pelayanan Terhadap Kepuasan Pengguna Sistem Informasi Pada Bank Umum Di Bandung. IRWNS , 9-15.

Sosiawan, E. A. (2015, June). Tantangan dan Hambatan dalam implementasi E-Government di Indonesia. In Seminar Nasional Informatika (SEMNASIF) (Vol. 1, No. 5).

Sugiyono. (2014). Metode Penelitian Bisnis. Bandung: Alfabeta.

Veeramootoo, N., Nunkoo, R., \& Dwivedi, Y. K. (2018). Apa Yang Menentukan Keberhasilan Layanan EGovernment? Validasi Model Integratif Kelanjutan Penggunaan E-Filing. Government Information Quarterly (2018) , 1-14.

Widiani, Y. N., \& Abdullah. (2018). Kualitas Pelayanan E-Government Melalui Aplikasi E-Filing Kantor Pelayanan Pajak Pratama Bandung Cibeunying Terhadap Kepuasan Pengguna Aplikasi. Jurnal Riset Bisnis dan Manajemen , 88-96. 